\title{
HABLANDO EN NOMBRE PROPIO ${ }^{1}$
}

\section{Por Bernhard WALDENFELS}

Si acepto, no sin vacilaciones, la invitación a decir algo sobre mis propios esfuerzos intelectuales, los incluiria en un tipo de fenomenología abierta y dispuesta al cambio. La caracterizaría como el desarro110 de una fenomenología estructural-existencial en el sentido de Merleau-Ponty, que evoluciona hacia una fenomenología responsiva en la que la intencionalidad (intencionar, aprehender como algo) se transforma en una responsividad (responder a apelaciones) ${ }^{2}$. Así, aquello a lo que respondemos es siempre más que aquello que damos por respuesta en determinadas circunstancias y en el marco de órdenes determinados. De esta manera, la racionalidad se puede comprender como racionalidad responsiva que surge del responder creativo; que por tanto no está dada previamente en las cosas y no puede distribuirse simétricamente entre diversos interlocutores.

Realicé mis estudios de filosofía y, paralelamente a ellos, de psicología, filología clásica e historia en Bonn, Innsbruck, Munich y París. Los comienzos estuvieron marcados por los estudios de filosofía clásica, sobre todo con Helmut Kuhn y Kurt von Fritz, de los que nació mi tesis doctoral dedicada al arte platónico del diálogo (Das sokratiscbe Fragen, Meisenheim 1961). Los estímulos que recibí de Ricoeur y especialmente de Merleau-Ponty durante mi estancia

${ }^{1}$ Los traductores del artículo del Profesor B. Waldenfels, «El desfondamiento del sentido", que aparece en este número de Investigaciones fenomenológicas, créamos que podría ser de interés que el citado texto fuera precedido por unas consideraciones del propio autor sobre su itinerario filosófico. Así se lo hicimos saber al profesor Waldenfels, quien amablemente redactó para la ocasión el siguiente escrito. Por ello le expresamos nuestro más sincero agradecimiento (nota de los traductores).

2 El término Responsivität, que procede originariamente de la medicina, se refiere a la capacidad de un organismo para 'responder' a las exigencias del medio en que vive (nota aclaratoria de B. Waldenfels). 
académica en París me condujeron por el camino de la fenomenología. En mi escrito de habilitación: Das Zwischenreich des Dialogs. Sozialphilosophische Untersuchungen in Anscbluss an Edmund Husserl (Den Haag 1971), me esfuerzo por transferir el enfoque filosóficotranscendental de Husserl a una dialógica fundada intercorporalmente, en la que lo propio y lo extraño aparecen como algo igualmente originario. Los autores de referencia más importantes de mi propio pensamiento son, junto con Platón (con Nietzsche al fondo), Husserl, Merleau-Ponty y Levinas, y con ciertas restricciones Foucault y Derrida.

Desde los años setenta ha intentado, en continua revisión de los textos husserlianos, proseguir la Fenomenología de la existencia y coexistencia corporales de Merleau-Ponty en el sentido de una teoría del comportamiento no behaviorista (Der Spielraum des Verbaltens. Fankfurt/M. 1980) y de un mundo de la vida plural, no fundamentalista (In den Netzen der Lebenswelt. Frankfurt/M. 1985). Junto a eso desempeña un importante papel la discusión permanente con las teorias sociales de Schützt, Mead y Habermas, y con las ciencias humanas y sociales. Hay que añadir a esto la discusión con el marxismo, estimulada por marxistas críticos y disidentes de la Europa del Este, que me parecía relevante para quitarle a la fenomenología su ingenuidad política y comprender el mundo de la vida como mundo de conflictos sociales (cf. los volúmenes que edité juntamente con J. M. Broekman y A. Pazanin: Phänomenologie und Marxismus. Frankfurt/M. 1977-79). La filosofía analítica fue un importante interlocutor, sobre todo en el afinamiento del instrumental metódico de la fenomenología. Como merleau-pontyano y como lector de Bühler, Saussure y Jakobson, nunca he tenido buena opinión del así llamado linguistic turn, pues la mitad del mismo me era evidente (que no hay intuiciones puras, que todo lo experimentado muestra determinadas estructuras de significado), y la otra mitad me resultaba cuestionable (que todo sentido tiene que pasar por el filtro de expresiones lingüísticas o que "todo es lenguaje", como dijo Gádamer). Frente a la teoría comunicativa de la nueva escuela de Frankfurt, me parecía importante insistir en que las estructuras prepredica- 
tivas de la experiencia no se pueden degradar al nivel previo de la formación argumentativa del consenso. La fase de mi filosofar aquí esbozada la incluiría en una fenomenología estructural-existencial en la que la pluralidad de referencias y la ambigüedad de los fenómenos ocupan el lugar central.

El paulatino cambio de prioridades, provocado entre otras cosas por la lectura de Foucault, de cuyos textos me he ocupado desde principios de los años setenta, llevó a que el problema del orden y, más concretamente, el problema de los órdenes variables, limitados, pasara a ocupar el lugar central. Estos órdenes, en contraposición con los tradicionales, que tienen un carácter totalizador y fundante, son contingentes. Surgen mediante procesos de selección y exclusión de posibilidades, y la incomposibilidad de campos de posibilidad (Merleau-Ponty) conduce a conflictos que no se pueden dirimir mediante fundamentaciones suficientes (Ordnung im Zwielicht. Frankfurt/M. 1987). De aqui se derivan dos haces de problemas. Por una parte, nos encontramos con el problema de que la experiencia sólo es posible a través de la reducción de un exceso de posibilidades. Pero, por otra parte, la multiplicación de las posibilidades y la mezcla de códigos, que pasa a ser el tema central en los autores posmodernos, no da ninguna repuesta a lo que hay que decir y hacer. Este segundo problema remite a las pretensiones que, a falta de un orden que abarque todas las tendencias y dirima todos los conflictos, se presentan como una pretensión excesiva (Überanspruch). Impulsado por este problema son dos los ámbitos temáticos que me han tenido ocupado los últimos años: la pregunta por lo extraño, que como apelación (appeal/claim) de lo extraordinario supera las fronteras de nuestro respectivo orden personal y colectivo (Der Stachel des Fremden. Frankfurt/M. 1990), y la pregunta por un comportamiento que satisface la apelación de un extraño y que trato de comprender como responsividad (cf. sobre esta expresión las investigaciones médicas de Kurt Goldstein). Ahora estoy trabajando en una amplia 
obra, Zur Logik der Antwort ${ }^{3}$, en la que abordo los antiguos enfoques filosófico-dialógicos pero tratando de liberarlos de las garras de una razón comunicativa. Entre el que pregunta y el que responde no hay simetría alguna, no hay una instancia de un tercero que dirima, que pueda tender un puente sobre el abismo (Abgruna) que separa la pregunta y la respuesta. Con ello, la concepción de la responsividad se encuentra al mismo nivel que la concepción fenomenológica usual de la intencionalidad, que la concepción analítica de regularidad y que la concepción pragmática de la practicabilidad, sin embargo, al mismo tiempo, constituye un claro contraste con respecto a ellas. En la elaboración de esta clase de fenomenología responsiva estoy particularmente cerca de Levinas, pero también del último Merleau-Ponty. No se trata con ello de una ética independiente, sino de aspectos y huellas éticos que se pueden distinguir desde el principio en toda experiencia y que incluye también nuestra relación con la naturaleza.

Desde un punto de vista histórico habría que mencionar mi monografía Phänomenologie in Frankreich (Frankfurt/M. 1983), en la que intento mostrar la variedad y la riqueza mediadora de la fenomenología francesa, que durante décadas fue la filosofía dominante en ese país. Esta obra terminaba con un capítulo titulado «phänomenologie im Widerstreit», es decir, con una discusión entre la fenomenología y el estructuralismo, en la que se pone en cuestión las posibilidades de supervivencia de la fenomenología, El proyecto se debió a estímulos de Herbert Spiegelberg. En una Einführung in die Phänomenologie (München 1992) aparecida recientemente presto especial atención a la diversidad geográfica de la fenomenología y a su repercusión en las diferentes ramas de la ciencia.

(Traducción: Raúl Castroviejo Fernández Jesús Miguel Díaz Alvarez)

${ }^{3}$ El libro aquí anunciado acaba de ser publicado con el título Antwortregister, Suhrkamp Verlag, Frankfurt a. M., 1994. (Nota de los traductores). 